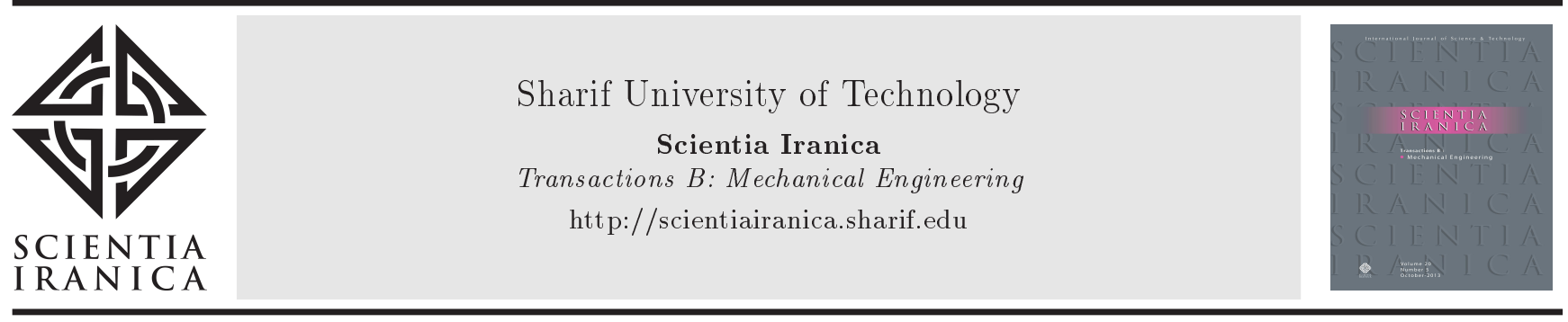

Research Note

\title{
Hydromagnetic Blasius-Sakiadis flows with variable features and nonlinear chemical reaction
}

\author{
R.L.V Renuka Devi ${ }^{a}$, S.V. Siva Rama Raju ${ }^{\text {, C.S.K. Rajuc }}{ }^{c}$ S.A. Shehzad ${ }^{d, *}$, \\ and F.M. Abbasi ${ }^{\mathrm{e}}$ \\ a. Department of Mathematics, Sri Venkateswara University, Tirupati-517502, India. \\ b. Department of Mathematics, Abu Dhabi Polytechnic, Abu Dhabi, United Arab Emirates. \\ c. Department of Mathematics, GITAM School of Science, Bangalore-561203, Karnataka, India. \\ d. Department of Mathematics, COMSATS University Islamabad, Sahiwal 57000, Pakistan. \\ e. Department of Mathematics, COMSATS University Islamabad, Islamabad 44000, Pakistan.
}

Received 26 September 2019; received in revised form 4 October 2020; accepted 17 May 2021

KEYWORDS
Viscous ratio
parameter;
Non-uniform heat
source-sink;
Variable conductivity;
Blasius-Sakiadis flows;
Chemical reaction.

\section{Introduction}

The fluid that flows across a surface or sheet has numerous applications in different branches of science, technology, and industry. Therefore, the significance of the investigation of this kind of fluid flows under different conditions has been highlighted more than ever. The concept of fluid flow over a horizontal stationary

\footnotetext{
*. Corresponding author.

E-mail address: ali_qaur0@yahoo.com (S.A. Shehzad)
}

plate under constant velocity was first introduced by Blasius [1]. Sakiadis [2] proposed another problem in which the plate moved with some constant velocity. In Blasius-Sakiadis flows, the heat transportation analysis occupies the major part. Hence, a considerable focus has been given to different types of heat transfer conditions. Pop and Watanabe [3] investigated the injection or suction on the laminar boundary-layer flow induced by continuous movement of sheet. Ishak et al. [4] considered the impact of thermal radiation on laminar flow across a moveable plate. Yao et al. [5] studied heat transportation in Newtonian fluid through a convectively bounded shrinking surface. They took 
into account the behavior of fluid temperature that was different from that of the prescribed wall temperature cases. Cortell [6] studied the boundarydriven quiescent fluid flow under nonlinear radiation. He observed that the temperature ratio and radiation constraints exhibited opposite behavior in terms of temperature distribution. Khan et al. [7] evaluated the Blasius-Sakiadis flow problems of Casson fluid with viscous dissipation. They concluded that both problems exhibited inverse behavior in terms of velocity distribution. Olanrewaju et al. [8] analyzed a convective boundary condition applied to Sakiadis and Blasius flows. They noticed an increment in temperature distribution with Eckert number in Blasius-Sakiadis flows. Sheikholeslami [9] employed a numerical technique to evaluate the behavior of entropy in nanofluid flow through the impact of Lorentz force. He also elaborated the nature of distinct involved parameters and their effects on fluid flow quantities by plotting streamlines and contours. In another study, Sheikholeslami [10] considered the hydromagnetic water- $\mathrm{Al}_{2} \mathrm{O}_{3}$ nanofluid flow induced by permeable medium. He carried out a comparative analysis to justify the validity of the present numerical technique. More novel studies on heat transfer analysis of fluid flow are found in [11-17].

Investigation of electrically conducting fluids in the case of Sakiadis and Blasius flows is of significance in different sectors such as glass painting, food processing, and automobiles. Heat transportation in hydromagnetic power-law fluid was reported by Kumari and Nath [18]. They noted that the friction factors and rate of heat transport increased in stronger magnetic fields. Akbar et al. [19] addressed the MHD nanofluids flow under thermally radiative convective conditions. Devi and Suriyakumar [20] evaluated the effects of the magnetic field on Sakiadis-Blasius flow of nanofluids. They took into consideration the opposite attitude of velocity in Blasius-Sakiadis flow cases with the enhanced values of Hartman parameter. Isa et al. [21] studied the hydro magnetic mixed conduction boundary-driven flow in the presence of exponential temperature distribution. Hamad et al. [22] studied the magneto hydrodynamic stagnation point flow on a preamble flat plat. Ferdows et al. [23] performed computations to examine the MHD free-convected mass transport in nonlinear fluid flow induced by moving sheet. Ullah et al. [24] described the homotopic asymptotic approach to discuss the Maxwell fluid flow under Lorentz field. Khan et al. [25] disclosed the heterogeneous and homogeneous reaction behaviors in magnetized Casson material flow subject to electromagnetic force. Ramli et al. [26] examined the nature of MHD ferro-liquid flow under uniform heat diffusion and second-order slip phenomena. Kumar et al. [27] pointed out the behavior of chemical reactive Williamson fluid flow with magnetic field aspects. They employed the numerical technique to elucidate the solutions to the governing problems. Thermal radiative nanofluid flows with magneto-hydrodynamic and accelerated ramped temperature effects were discussed by Hussain et al. [28]. Abbasi et al. [29] examined the second law phenomenon in hydromagnetic peristaltic nanofluid flow under ohmic dissipation and Hall current phenomenon. The solutions were then elaborated with the help of a numerical procedure. Entropy optimization of electrically conducting nano-material flow induced by the variable thicked sheet was achieved by Wang et al. [30]. Heat transmission analysis of nonlinear convective flow of Walter's B material flow under gyrotactic micro-organisms phenomenon was then reported by Khan et al. [31]. Abbas et al. [32] pointed to the effect of second-order slip on the magnetized nanomaterial flow under energy activation processes.

Inspired by the above-mentioned literature, the present study aims to find the mixed convective conditions on hydromagnetic Blasius-Sakiadis flows with variable properties and nonlinear chemical reaction. The flow was generated by the time-dependent movement of the surface. Numerical illustrations of the results were reported for the quantities of practical interests. The set of governing equations was evaluated and presented through several graphs and tables.

\section{Mathematical formulations}

Time-dependent naturally convected Blasius-Sakiadis flow with variable properties and nonlinear chemical reaction was taken into consideration in this study. Brownian movement and thermophoresis force aspects were also considered due to nanofluid. The surface was stretched with a velocity of $U_{w}(x, t)=\frac{a x}{1-c t}$. The governing expressions for the present case are [15-19]:

$$
\begin{aligned}
\frac{\partial v}{\partial y}+ & \frac{\partial u}{\partial x}=0 \\
v \frac{\partial u}{\partial y}+ & u \frac{\partial u}{\partial x}+\frac{\partial u}{\partial t}=g\left(\beta_{c}\left(C-C_{\infty}\right)+\beta_{T}\left(T-T_{\infty}\right)\right) \\
& +\frac{1}{\rho} \frac{\partial}{\partial y}\left(\mu_{f} \frac{\partial u}{\partial y}\right)-\frac{\vartheta}{K_{0}} u-\frac{\sigma B_{0}^{2}}{\rho} u \\
\rho C_{p} & \left(v \frac{\partial T}{\partial y}+u \frac{\partial T}{\partial x}+\frac{\partial T}{\partial t}\right)=\frac{\partial}{\partial y}\left(K(T) \frac{\partial T}{\partial y}\right) \\
& +\frac{16 \sigma^{*} T_{\infty}^{3}}{3 k^{*}} \frac{\partial^{2} T}{\partial y^{2}}+q^{\prime \prime \prime}+\mu_{f}\left(\frac{\partial u}{\partial y}\right)^{2} \\
& +\tau\left(\begin{array}{c}
D_{B} \frac{\partial T}{\partial y} \frac{\partial C}{\partial y} \\
+\frac{D_{T}}{T_{\infty}}\left(\frac{\partial T}{\partial y}\right)^{2}
\end{array}\right),
\end{aligned}
$$




$$
\begin{gathered}
v \frac{\partial C}{\partial y}+u \frac{\partial C}{\partial x}+\frac{\partial C}{\partial t}=D_{B} \frac{\partial^{2} C}{\partial y^{2}}+\frac{D_{T}}{T_{\infty}} \frac{\partial^{2} T}{\partial y^{2}} \\
-k_{0}^{2}\left[\frac{T}{T_{\infty}}\right]^{2} \mathrm{e}^{\left(-E_{a} / \kappa T\right)}\left(C-C_{\infty}\right),
\end{gathered}
$$

with the boundary conditions:

i) Blasius problem:

$$
\left.\begin{array}{l}
v=0, u=0, K_{\infty} \frac{\partial C}{\partial y}=-h_{f_{2}}\left(C-C_{\infty}\right), \\
K_{\infty} \frac{\partial T}{\partial y}=-h_{f_{1}}\left(T-T_{\infty}\right), \text { at } y=0, \\
u=U_{w}, C=C_{\infty}, T=T_{\infty}, \text { as } y \rightarrow \infty
\end{array}\right\}
$$

ii) Sakiadis problem:

$$
\left.\begin{array}{l}
v=0, u=U_{w}, K_{\infty} \frac{\partial C}{\partial y}=-h_{f_{2}}\left(C-C_{\infty}\right), \\
K_{\infty} \frac{\partial T}{\partial y}=-h_{f_{1}}\left(T-T_{\infty}\right), \text { at } y=0, \\
u=0, T=T_{\infty}, C=C_{\infty} \text { as } y \rightarrow \infty .
\end{array}\right\}
$$

The velocity components are $u$ and $v$ in the $x$ and $y$-directions, respectively; $g$ is the acceleration of gravity; $\nu$ presents the kinematic viscosity; $\beta_{C}, \beta_{T}$ are the coefficients of concentration and thermal expansions, respectively; $C_{\infty}, T_{\infty}$ are the ambient concentration and temperature, respectively; $c_{p}$ is the specific heat. In addition, $K(T)$ shows the variable conductivity, $\rho$ the density, $k_{0}$ the chemical reaction rate, $\mathrm{e}^{\left(-E_{a} / \kappa T\right)}\left(C-C_{\infty}\right)\left(\frac{T}{T_{\infty}}\right)^{n}$ the Arrhenius function, $n$ the exponent, $E_{a}$ the activation energy, $\sigma^{*}$ the Boltzmann constant, and $k^{*}$ the Stefan constant. Further, $h_{f_{1}}$ and $h_{f_{2}}$ are the heat and mass transfer coefficients. The variable formula of thermal conductivity and viscosity can be expressed as:

$$
\begin{aligned}
& K(T)=K_{\infty}\left(1+\frac{\varepsilon}{\Delta T}\left(T-T_{\infty}\right)\right), \\
& \mu_{f}(T)=\frac{\mu_{\infty}}{\left(1+\omega\left(T-T_{\infty}\right)\right)}, \\
& q^{\prime \prime \prime}=\frac{K_{\infty} U_{w}}{x v}\left(\mathrm{~A}^{*}\left(T_{w}-T_{\infty}\right)+B^{*}\left(T-T_{\infty}\right)\right) .
\end{aligned}
$$

Here, $\Delta T=\left(T_{w}-T_{\infty}\right), T_{w}$ is the surface temperature; $K_{\infty}$, and $\mu_{\infty}$ are the thermal conductivity and viscosity of the fluid far away from the surface; $\varepsilon$ and $\omega$ are the smaller parameters called the conductivity and viscosity variations constraint, respectively; $A^{*}$ and $B^{*}$ are the time- and space-dependent heat sources or sink. $A^{*}$ and $B^{*}>0$ is for heat source and $A^{*}$ and $B^{*}<0$ for the heat sink. The similarity variables are expressed as follows:

$$
\begin{array}{ll}
\zeta=\left(\frac{a}{v(1-c t)}\right)^{\frac{1}{2}} y, & \psi=\left(\frac{v a}{(1-c t)}\right)^{\frac{1}{2}} x f(\zeta), \\
\theta(\zeta)=\frac{\left(T-T_{\infty}\right)}{\left(T_{w}-T_{\infty}\right)}, & \phi(\zeta)=\frac{\left(C-C_{\infty}\right)}{\left(C_{w}-C_{\infty}\right)}
\end{array}
$$

where $\psi(x, y, t)$ is the stream function expressed by the relation $(u, v)=(\partial \psi / \partial y,-\partial \psi / \partial x)$. Substituting Eqs. (2)-(4) and making use of Eqs. (7)-(9), we obtain:

$$
\begin{aligned}
& \frac{1}{(1+E \theta)} f^{\prime \prime \prime}-\frac{E}{(1+E \theta)^{2}} \theta^{\prime} f^{\prime \prime}+f f^{\prime \prime}-f^{\prime 2} \\
& -A\left(f^{\prime}+\frac{1}{2} \varsigma f^{\prime \prime}\right)-(M+K) f^{\prime}+\lambda_{T} \theta \\
& +\lambda_{c} \phi=0 \\
& \frac{A}{2} \varsigma \theta^{\prime}-f \theta^{\prime}-\frac{1}{\operatorname{Pr}}\left(\theta^{\prime \prime}+\frac{\varepsilon}{1+\varepsilon \theta} \theta^{\prime 2}\right) \\
& -\mathrm{Nb} \theta^{\prime} \phi^{\prime}-N t \theta^{2}-\mathrm{Ec} f^{\prime \prime 2}-\frac{1}{\operatorname{Pr}} N r \theta^{\prime \prime} \\
& -A^{*} f^{\prime}-B^{*} \theta=0, \\
& \frac{A}{2} \phi^{\prime} \varsigma-f \phi^{\prime}=\frac{1}{L e}\left(\phi^{\prime \prime}+\frac{N t}{\mathrm{Nb}} \theta^{\prime \prime}\right)-K r^{2}(1+n \gamma \theta) \\
& \quad \exp \left(-\frac{E_{1}}{1+\gamma \theta}\right) \phi
\end{aligned}
$$

Boundary conditions can be described as:

i) Blasius flow:

$$
\begin{aligned}
& f(0)=0, \quad f^{\prime}(0)=0, \quad \phi^{\prime}(0)=-\left(1-\mathrm{Bi}_{1} \phi(0)\right), \\
& \theta^{\prime}(0)=-\left(1-\mathrm{Bi}_{2} \theta(0)\right), \\
& f^{\prime}(\infty)=1, \quad \theta(\infty)=0, \quad \phi(\infty)=0 .
\end{aligned}
$$

ii) Sakiadis flow:

$$
\begin{aligned}
& f(0)=0, \quad f^{\prime}(0)=1, \quad \phi^{\prime}(0)=-\left(1-\mathrm{Bi}_{1} \phi(0)\right), \\
& \theta^{\prime}(0)=-\left(1-\mathrm{Bi}_{2} \theta(0)\right), \\
& f^{\prime}(\infty)=0, \quad \theta(\infty)=0, \quad \phi(\infty)=0,
\end{aligned}
$$

where $A=c / a$ is the unsteady constraint, $M=$ $\frac{\sigma B_{0}^{2}(1-c t)}{\rho a}$ the magnetic field constraint, $E=$ $\frac{\rho a}{\left(T_{w}-T_{\infty}\right)}$ the viscosity variation constraint, $K=$ $\frac{v(1-c t)}{k_{0} a}$ the porosity constraint, $\mathrm{Ec}=\frac{U_{w}{ }^{2}}{C_{p}\left(T_{\infty}-T_{r}\right)}$ the Eckert number, $\gamma=\frac{T_{w}-T_{\infty}}{T_{\infty}}$ the temperature ratio, $K r^{2}=\frac{k_{0}{ }^{2} c}{v}$ the chemical reaction parameter, $E_{1}=\frac{E_{a}}{k T_{\infty}}$ the activation energy, $N r=\frac{16 \sigma^{*} T_{\infty}^{3}}{3 k^{*} K}$ the radiation constraint, $\operatorname{Pr}=v / \alpha_{\infty}$ the Prandtl number, $\mathrm{Bi}_{1}=\frac{h_{f_{1}}}{k_{\infty}} \sqrt{\frac{v(1-c t)}{a c}}$ the thermal Biot number, $\mathrm{Bi}_{2}=\frac{h_{f_{2}}}{k_{\infty}} \sqrt{\frac{v(1-c t)}{a c}}$ the concentration Biot number, $N t=\frac{\tau D_{T} \Delta T}{v T_{\infty}}$ the thermophoresis, $\mathrm{Nb}=$ $\frac{\tau D_{B} \Delta C}{v}$ the Brownian motion, $\lambda_{T}=\frac{g \beta_{T}\left(T_{w}-T_{\infty}\right)}{a U_{w}}$ the thermal buoyancy, and $\lambda_{C}=\frac{g \beta_{c}\left(C_{w}-C_{\infty}\right)}{a U_{w}}$ the concentration buoyancy. 
The expressions for friction factors, local Sherwood, and Nusselt numbers can be designed as follows:

$$
\begin{aligned}
& C_{f}=\frac{\tau_{w}}{\rho U_{w}{ }^{2} / 2}, \quad \mathrm{Sh}_{x}=\frac{x j_{w}}{D_{B}\left(C_{w}-C_{\infty}\right)}, \\
& \mathrm{Nu}_{x}=\frac{x q_{w}}{k_{\infty}\left(T_{w}-T_{\infty}\right)},
\end{aligned}
$$

where the skin friction $\tau_{w}$ and mass and heat transport rates are $j_{w}, q_{w}$ which can be expressed through the relations:

$$
\begin{aligned}
& \tau_{w}=\mu\left(\frac{\partial u}{\partial y}\right)_{y=0}, \quad j_{w}=-D_{B}\left(\frac{\partial C}{\partial y}\right)_{y=0}, \\
& q_{w}=-k\left(\frac{\partial T}{\partial y}\right)_{y=0} .
\end{aligned}
$$

Substituting Eq. (9) into Eqs. (15) and (16), we obtain:

$$
\begin{aligned}
\operatorname{Re}_{x}^{1 / 2} C f & =\left(1+\frac{1}{(1+E \theta)}\right) f^{\prime \prime}(0), \operatorname{Re}_{x}^{-1 / 2} \mathrm{Sh} \\
& =-\phi^{\prime}(0), \operatorname{Re}_{x}^{-1 / 2} \mathrm{Nu} \\
& =-\left(\frac{4}{3} N r+1+\varepsilon+\varepsilon \theta^{\prime}(0)^{2}\right) \theta^{\prime}(0),
\end{aligned}
$$

where $\operatorname{Re}_{x}=U_{w} x / \nu_{f}$ is the local Reynolds number.

\section{Results and discussion}

Numerical solutions were constructed to evaluate the nature of Eckert number, Biot numbers, chemical reaction parameter, Brownian movement, thermal radiation, magnetic field, thermophoresis and porosity constraints on non-dimensional temperature, velocity, and concentration by considering $(E=0.2, \varepsilon=0.2)$ and $(E=0, \varepsilon=0)$. Moreover, the results of local frictionfactors coefficient, rate of heat, and mass transports are communicated through numerical data for SakiadisBlasius flows. The values for non-dimensional constraints are $K=0.5, n=2 ; K r=0.2, \operatorname{Pr}=0.2, \lambda_{T}=$ $0.3, \lambda_{c}=0.2, \mathrm{Ec}=0.2, \mathrm{Nb}=0.3, N t=0.2, M=0.5$, $\mathrm{Bi}_{1}=\mathrm{Bi}_{2}=0.2, E=0.2, \varepsilon=0.2, N r=0.5, A^{*}=0.2$, $B^{*}=0.2$. In this study, the graphs in dashed and solid lines represent the Blasius and Sakiadis flow problems.

Figures 1-3 exemplify the deviations of porosity constraint on $f^{\prime}(\zeta), \theta(\zeta)$, and $\phi(\zeta)$ fields. According to Figure 1, the participation of porous medium corresponds to high control in flow, thus slowing down its motion. Therefore, with improvement in porosity, resistance to liquid flow was elevated, thus suppressing the velocity in Blasius-Sakiadis flow cases. The contradictory movement can be perceived in temperature and concentration fields (see Figures 2 and 3). Figure 4

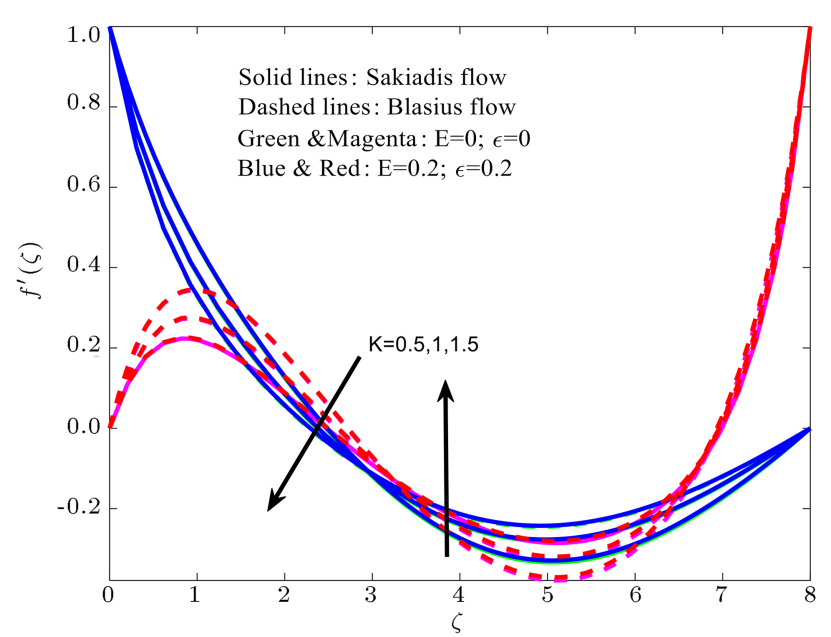

Figure 1. Velocity $f^{\prime}(\zeta)$ for distinct values of $K$.

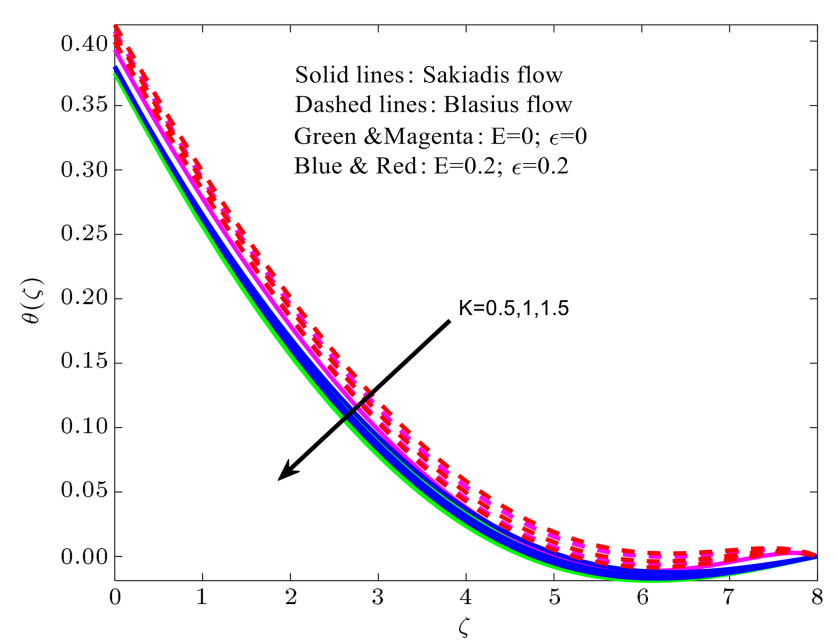

Figure 2. Temperature $\theta(\zeta)$ for different values of $K$.

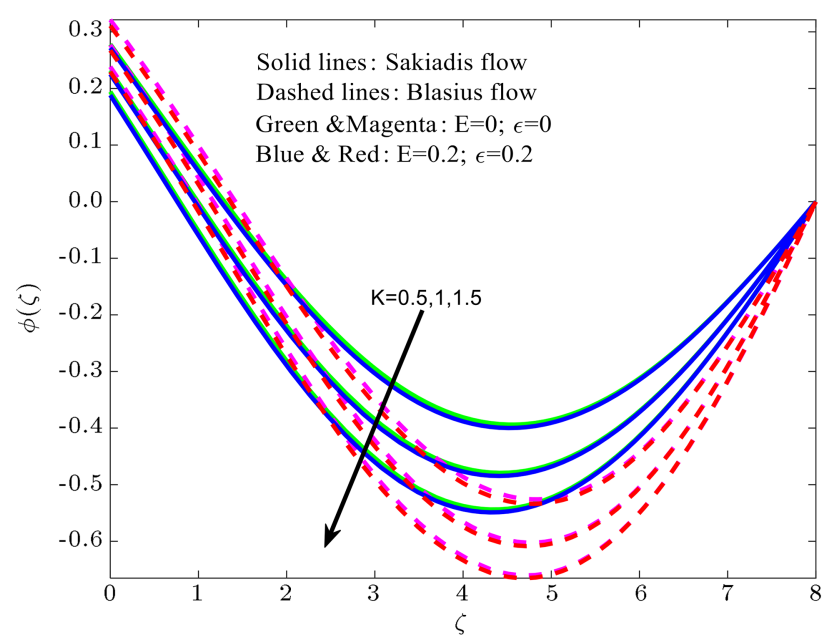

Figure 3. Concentration for distinct values of $K$.

shows the nature of Biot number $\mathrm{Bi}_{1}$ on temperature $\theta(\zeta)$ field. Biot number is the ratio of convection to conduction heat transport. It leads to higher temperature on the surface and weaker thermal layer. Figures 5 and 


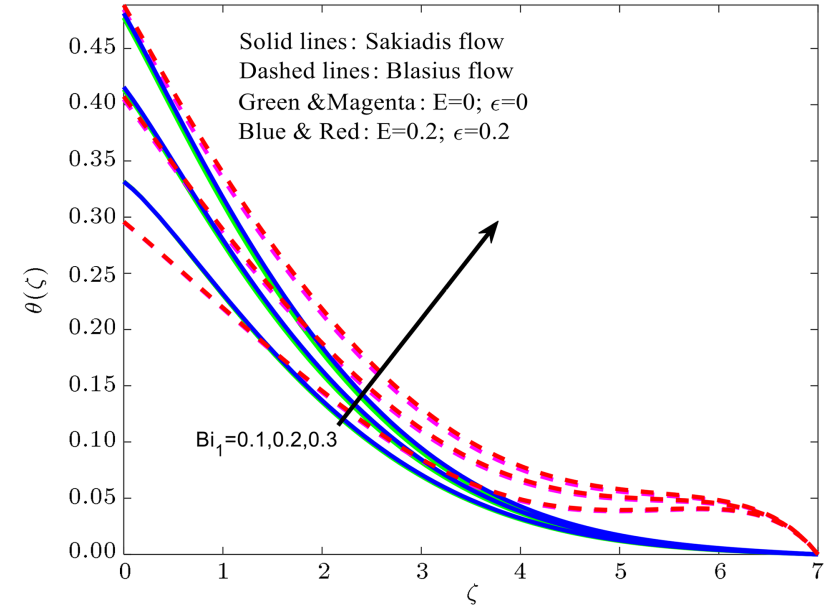

Figure 4. Temperature $\theta(\zeta)$ for distinct values of $\mathrm{Bi}_{1}$.

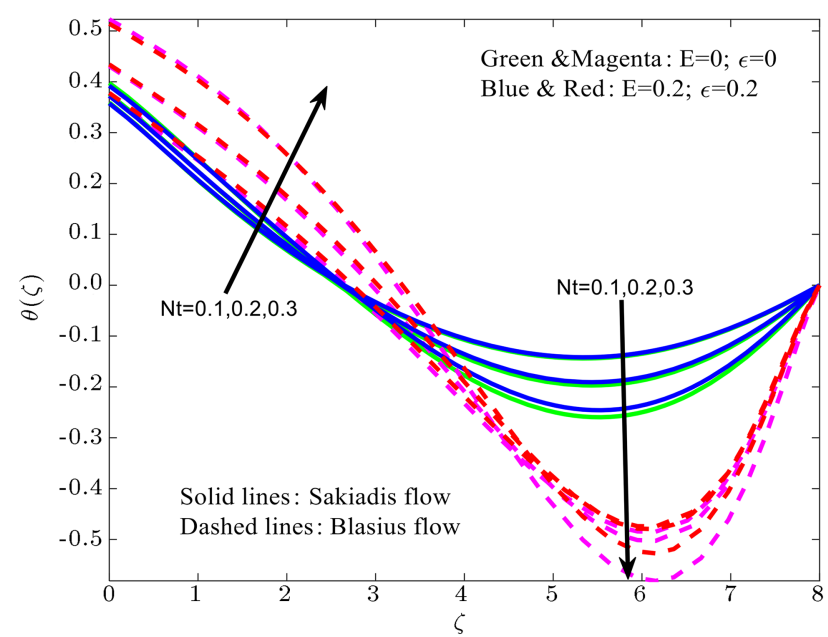

Figure 5. Temperature $\theta(\zeta)$ for diverse values of $N t$.

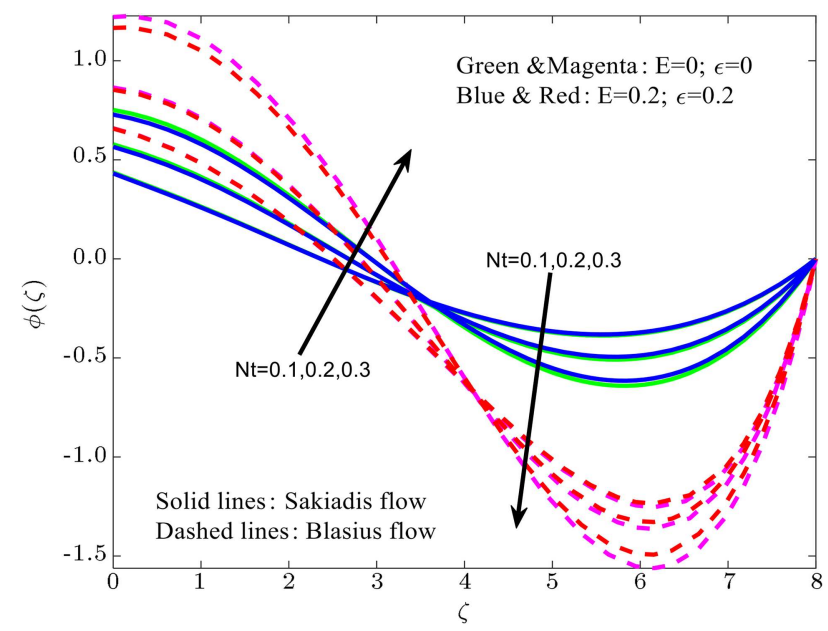

Figure 6. Concentration $\phi(\zeta)$ for distinct values of $N t$.

6 depict the part of thermophoretic $N t$ on $\theta(\zeta)$ and $\phi(\zeta)$ fields. The profiles of $\theta(\zeta)$ and $\phi(\zeta)$ are advanced upon increase in the value of $N t$ parameter. According to the findings, while the positive thermophoresis values

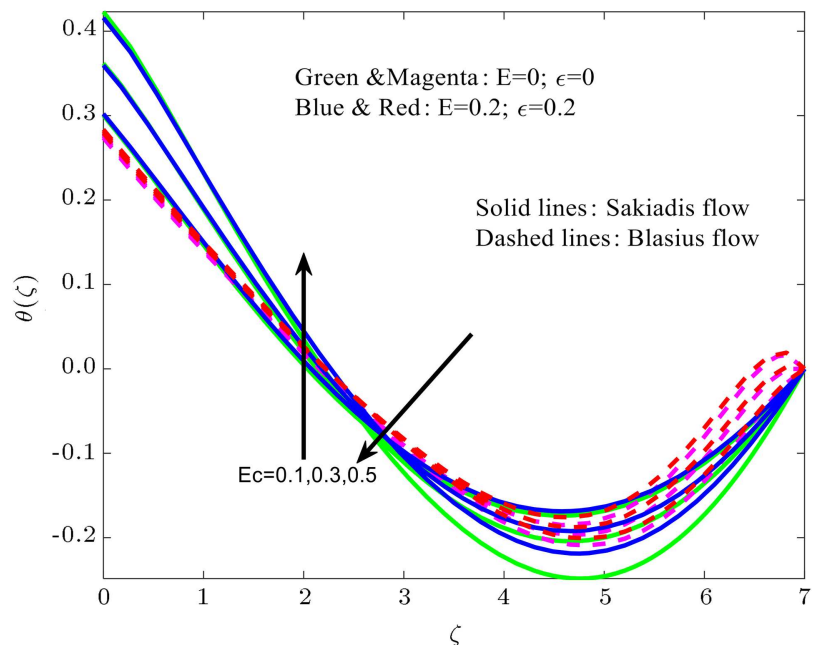

Figure 7. Temperature $\theta(\zeta)$ for distinct values of Ec.

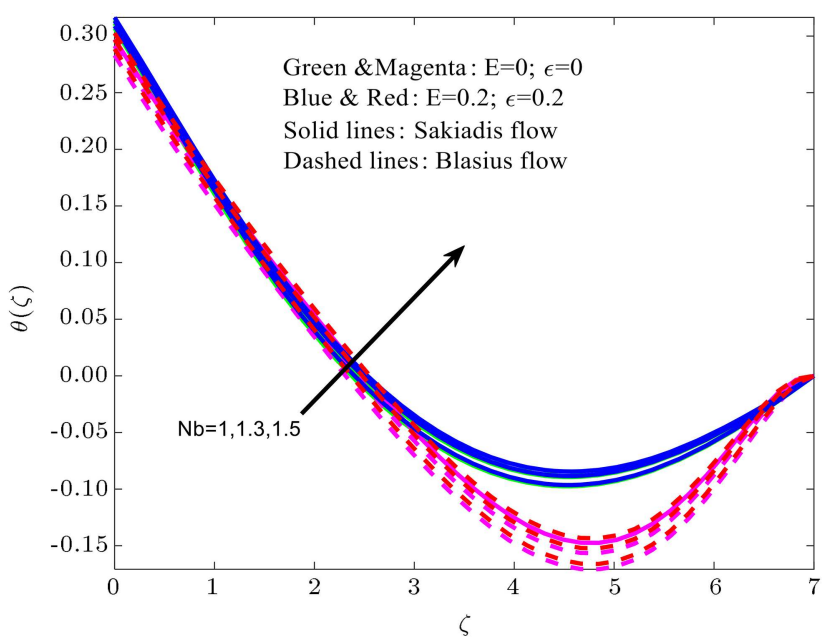

Figure 8. Temperature $\theta(\zeta)$ for distinct values of $\mathrm{Nb}$.

represent the cold surface, negative values show the hot surface. The temperature and concentration fields are far away from the surface. This phenomenon is reduced in the presence of nonlinear buoyancy forces.

The characteristics of Ec on $\theta(\zeta)$ in the presence and absence of viscosity and conductivity variations constraints are presented in Figure 7 for BlasiusSakiadis flow cases. According to this figure, the thickness of thermal layer increases with an increase in Ec. The Brownian movement $\mathrm{Nb}$ on $\theta(\zeta)$ and $\phi(\zeta)$ was done, as shown in Figures 8 and 9. Figure 8 describes the nature of $\theta(\zeta)$ for dissimilar $\mathrm{Nb}$. With an increment in $\mathrm{Nb}$, the temperature and concentration will decrease and increase (see Figure 9), respectively, mainly due to the fact that Brownian movement $\mathrm{Nb}$ takes place in nano-scale systems. The effects of magnetic parameter on $f^{\prime}(\zeta), \theta(\zeta)$, and $\phi(\zeta)$ are evaluated, as shown in Figures 10-12. Based on the observations, increase in $M$ decelerates $f^{\prime}(\zeta)$ and enriches $\theta(\zeta)$ and $\phi(\zeta)$ fields. The application of the magnetic field to electrically con- 
ducting liquid gave rise to resistive forces (retardation force) called Lorentz force. This Lorentz force is able to diminish the motion of boundary layer and progress

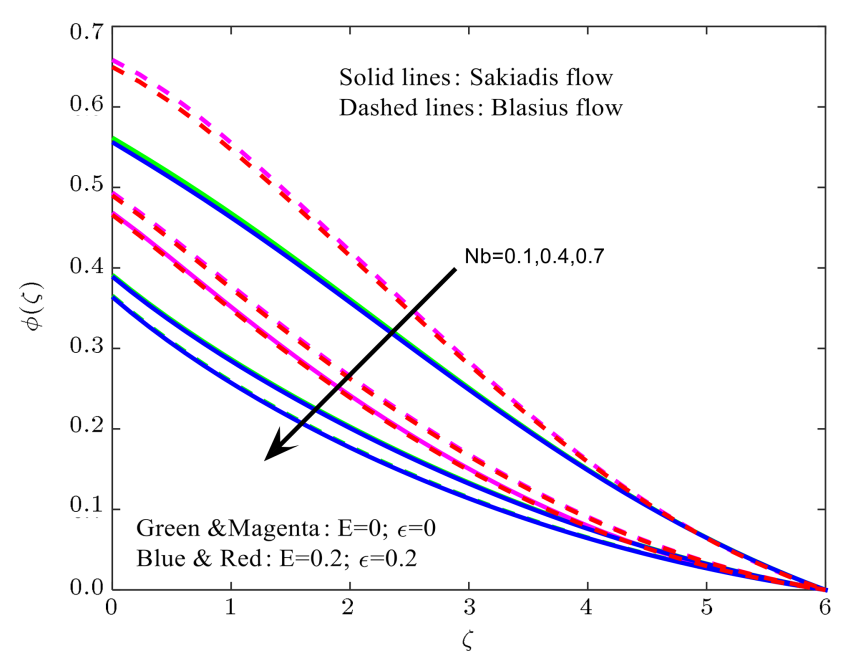

Figure 9. Concentration $\phi(\zeta)$ for dissimilar values of $\mathrm{Nb}$.

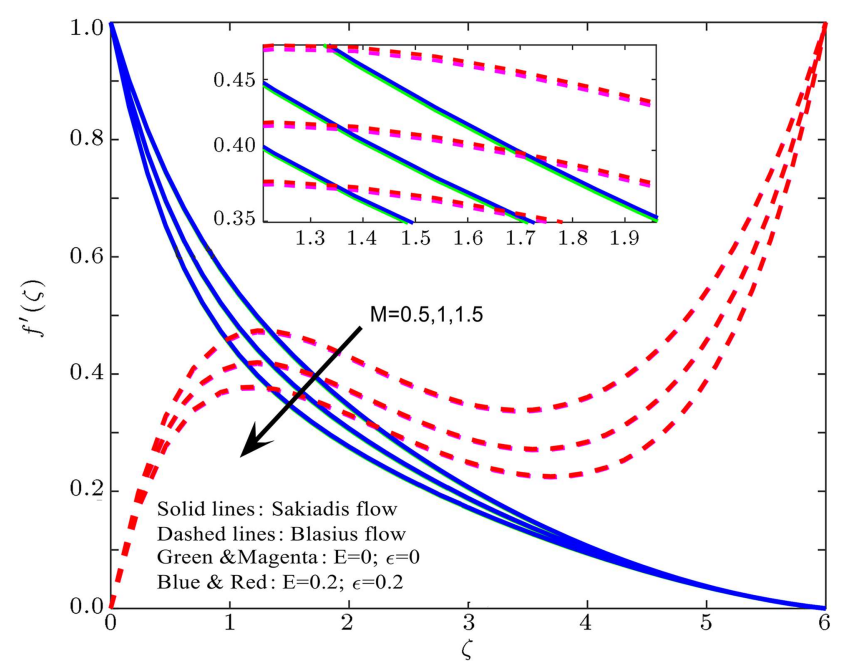

Figure 10. Velocity $f^{\prime}(\zeta)$ for distinct values of $M$.

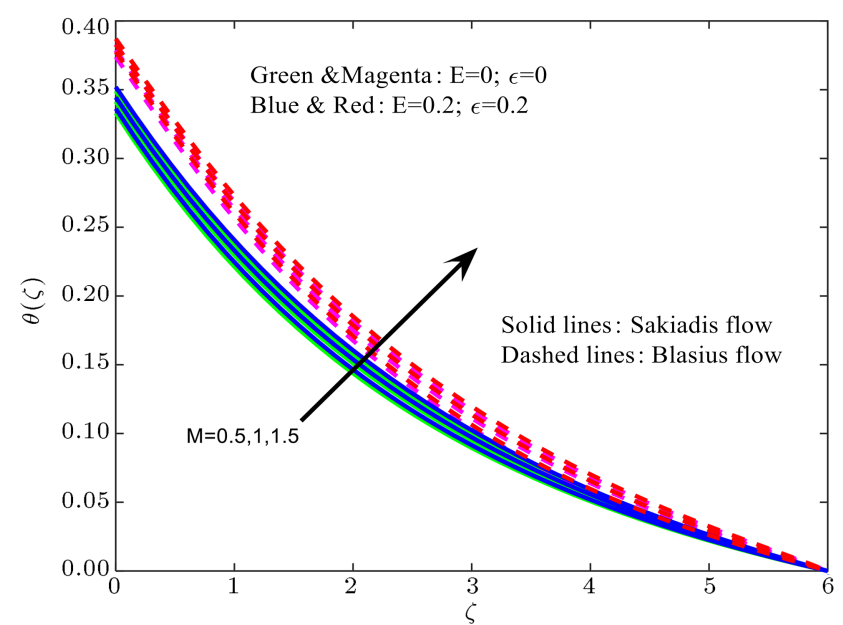

Figure 11. Temperature $\theta(\zeta)$ for different values of $M$. the concentration and temperature distributions in Blasius-Sakiadis flows.

The effects of different values of $N r$ on $\theta(\zeta)$ and $\phi(\zeta)$ are depicted in Figures 13 and 14. Figure 13 reports that the thickness of thermal layer increases with an increase in $N r$. This contradictory phenomenon can be reflected in $\phi(\zeta)$ profiles (see Figure 14). As expected, thermal radiation generates heat molecules which facilitate the improvement of the thermal boundary layer.

The participation of chemical reaction constraint is visualized in Figure 15, reporting that the larger chemically reactive constraint decelerates the concentration profiles for Blasius-Sakiadis flows. The chemical reaction here resulted in chemical consumption that consequently leads to decrement in concentration distributions. This chemical reaction has the ability to decrease the thickness of the solutal layer. The immersion of Biot number $\mathrm{Bi}_{2}$ thrusts up the concentration $\phi(\zeta)$ in Blasius-Sakiadis cases for either with or without

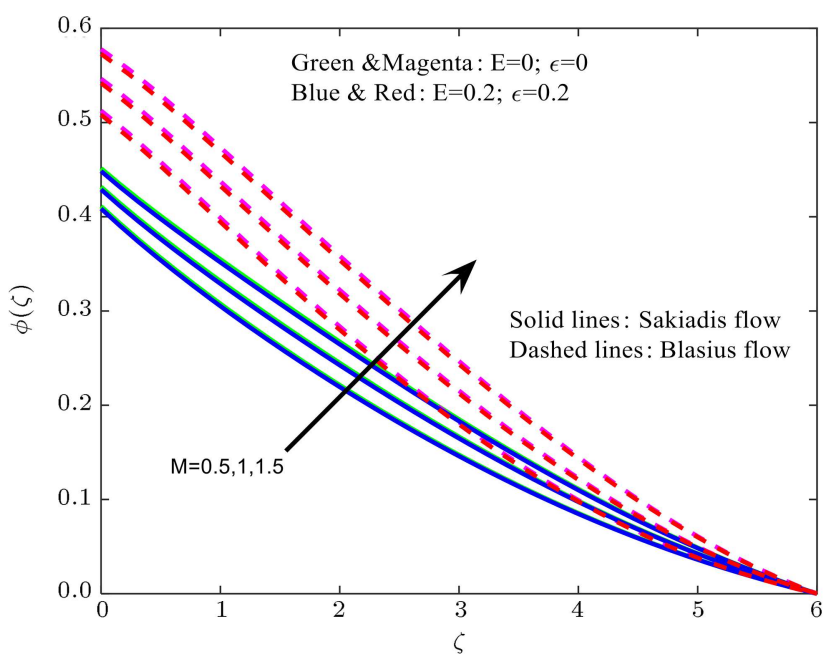

Figure 12. Concentration $\phi(\zeta)$ for distinct values of $M$.

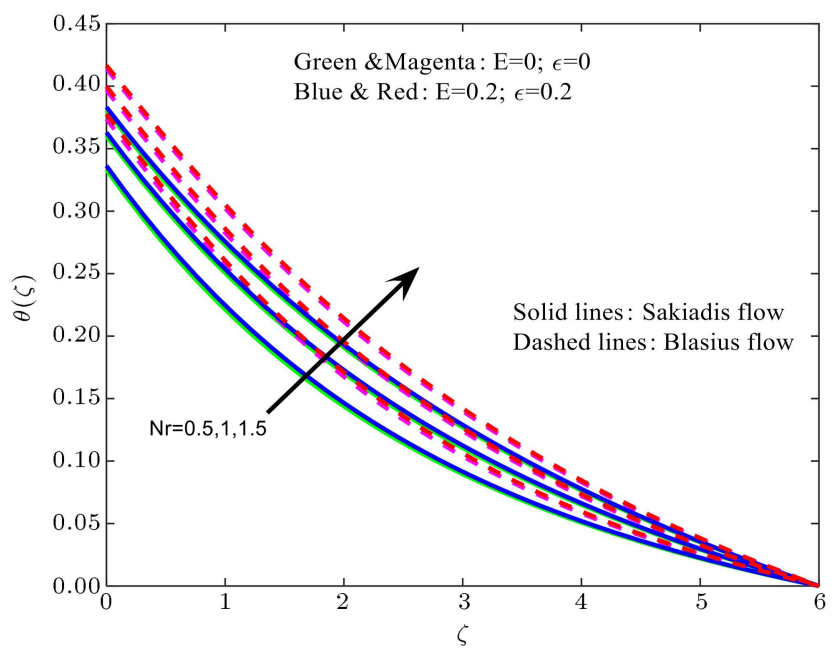

Figure 13. Temperature $\theta(\zeta)$ for distinct values of $N r$. 
variable properties (see Figure 16). Of note, the Blasius flow has a more significant concentration profile than that of the Sakiadis flow case. The association of

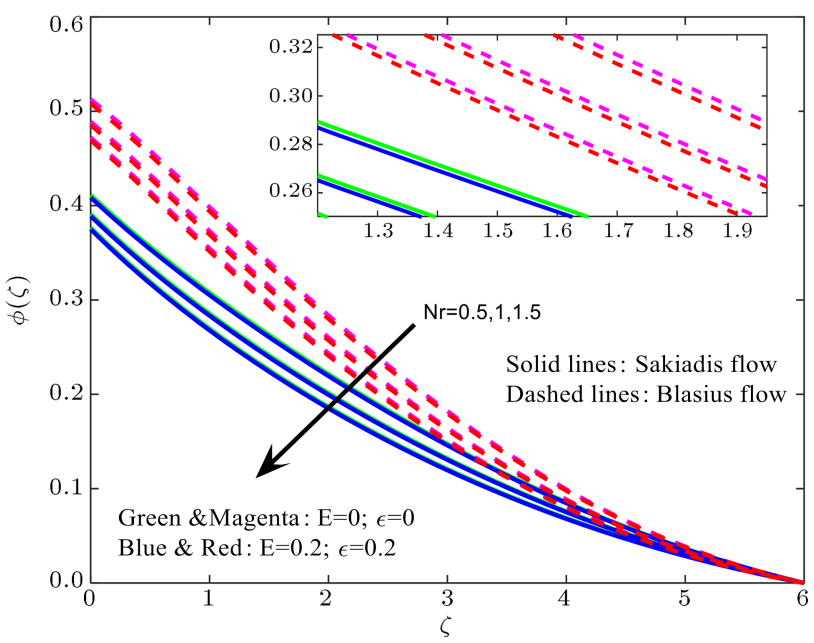

Figure 14. Concentration $\phi(\zeta)$ for various values of $N r$.

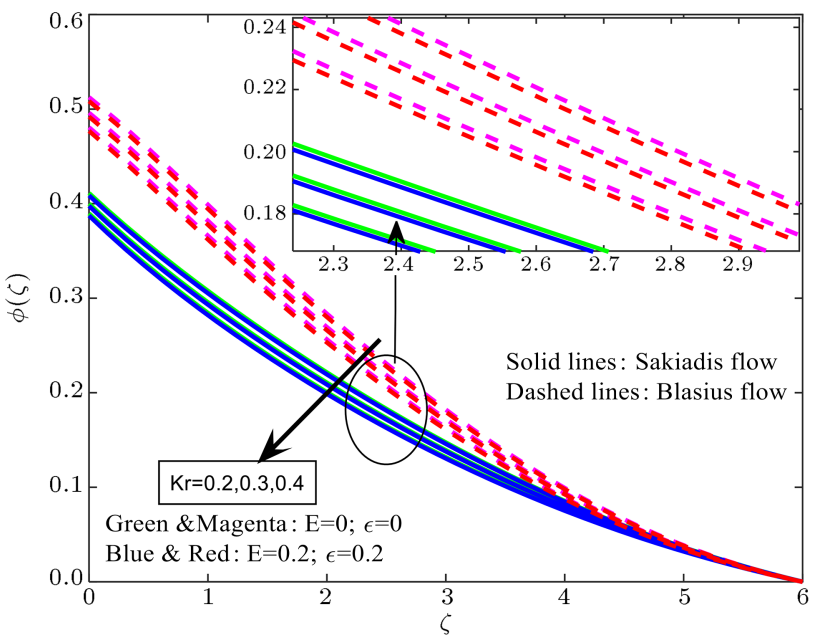

Figure 15. Concentration $\phi(\zeta)$ for different values of $K r$.

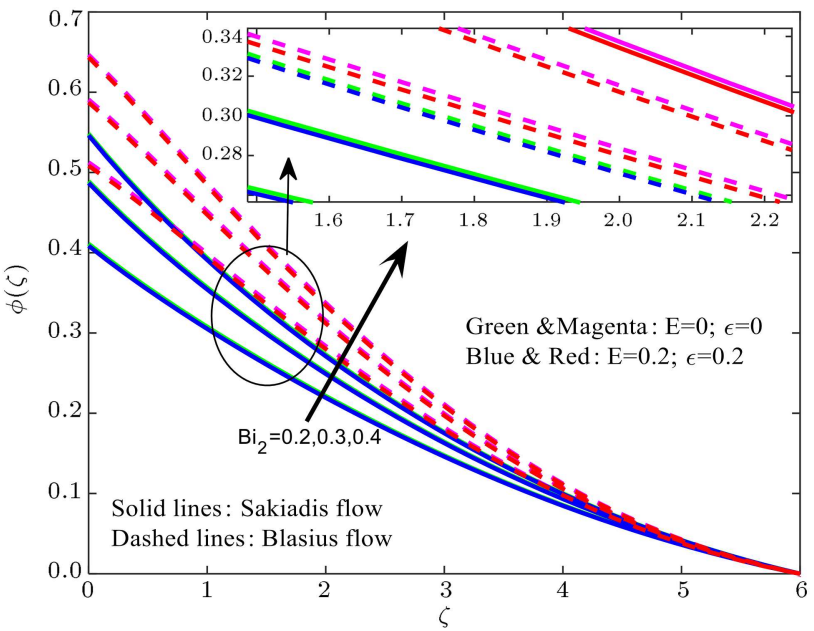

Figure 16. Concentration $\phi(\zeta)$ for different values of $\mathrm{Bi}_{2}$. dissimilar values of $A^{*}$ with $\theta(\zeta)$ and $\phi(\zeta)$ is shown in Figures 17 and 18 . As observed, the thickness of diffusion layer increased upon increasing $A^{*}$. The mixed performance can be seen with respect to $\theta(\zeta)$ profiles (see Figure 17). As expected, since $A^{*}$ acts as heat generation or absorption, it strengthens the thermal boundary layer near the boundary following the dominance of nonlinear chemical reaction (see Figure 18).

Table 1 illustrates that the current calculated results are in agreement with the results obtained from Grubka and Bobba [33], Ali [34], and Ishak et al. [35] in limiting circumstances for both Blasius-Sakiadis flow cases. Tables 2 and 3 depict the nature of variation of $\operatorname{Re}_{x}^{1 / 2} C f$ and $\operatorname{Re}_{x}^{-1 / 2} \mathrm{Nu}$ for distinct values of Biot numbers due to thermal diffusion, chemical reaction, Eckert number, thermophoresis, Brownian movement, non-uniform heat source or sink, thermal radiation, and magnetic field; in addition, porosity parameters are studied in the case of Blasius-Sakiadis in the presence $(E=0.2, \varepsilon=0.2)$ and absence $(E=0, \varepsilon=0)$ of viscosity variation and conductivity variation parameters. The effect of thermal radiation parameter increases

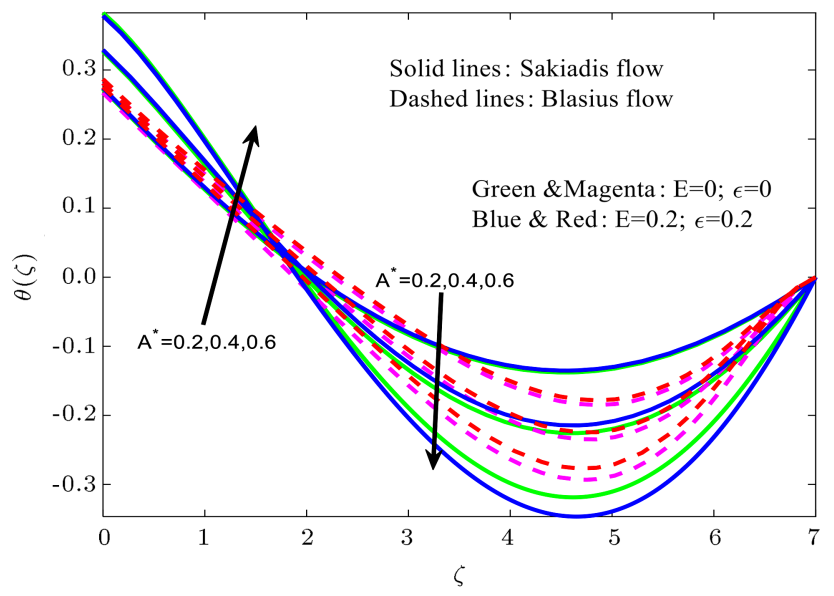

Figure 17. Temperature for different values of $A^{*}$.

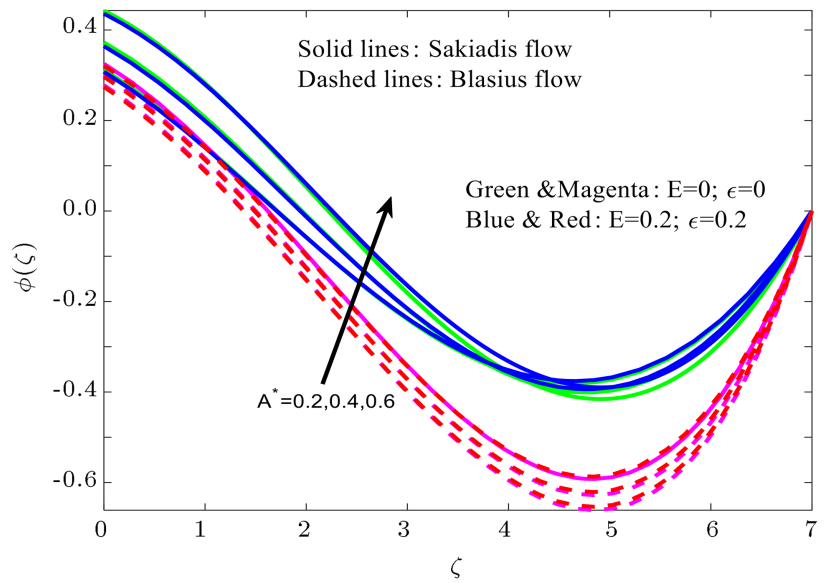

Figure 18. Concentration $\phi(\zeta)$ for dissimilar values of $A^{*}$. 
Table 1. Comparison between the data of $-\theta^{\prime}(0)$ and existing results in the absence of thermal radiation by setting $\mathrm{Ec}=K=\mathrm{Bi}_{1}=\mathrm{Bi}_{2}=K r=0$.

\begin{tabular}{cccccc}
\hline $\boldsymbol{\lambda}_{\boldsymbol{T}}$ & $\mathbf{P r}$ & Grubka and Bobba [33] & Ali [34] & Ishak et al. [35] & Present results \\
\hline & 0.72 & 0.8086 & 0.8058 & 0.8086 & 0.808836 \\
0.0 & 1.0 & 1.0000 & 0.9961 & 1.00000 & 1.000000 \\
& 3.0 & 1.9237 & 1.9144 & 1.9237 & 1.923687 \\
& 10.0 & 3.7207 & 3.7006 & 3.7207 & 3.720788 \\
& 10.0 & 12.2940 & - & 12.2941 & 12.30039 \\
0.0 & 1.0 & - & - & 1.6820 & 1.681921 \\
1.0 & & - & - & 1.7039 & 1.703910 \\
1.0 & 1.0 & - & - & 1.0873 & 1.087206 \\
2.0 & & - & - & 1.1423 & 1.142298 \\
3.0 & & - & - & 1.1853 & 1.185197 \\
\hline
\end{tabular}

Table 2. The values of $\operatorname{Re}_{x}^{1 / 2} C f$ and $\operatorname{Re}_{x}^{-1 / 2} \mathrm{Nu}$ for distinct values of the involved parameters in Sakiadis and Blasius flows in cases of $E=0$ and $\varepsilon=0$.

\begin{tabular}{|c|c|c|c|c|c|c|c|c|c|c|c|c|c|}
\hline \multirow[b]{2}{*}{$K$} & \multirow[b]{2}{*}{$\mathbf{B i}_{1}$} & \multirow[b]{2}{*}{$N t$} & \multirow[b]{2}{*}{$\mathrm{Nb}$} & \multirow[b]{2}{*}{ Ec } & \multirow[b]{2}{*}{$M$} & \multirow[b]{2}{*}{$A^{*}$} & \multirow[b]{2}{*}{$\mathrm{Bi}_{2}$} & \multirow[b]{2}{*}{$N r$} & \multirow[b]{2}{*}{$\boldsymbol{K r}$} & \multicolumn{2}{|c|}{$\operatorname{Re}_{x}^{1 / 2} C f$} & \multicolumn{2}{|c|}{$\operatorname{Re}_{x}^{-1 / 2} \mathrm{Nu}$} \\
\hline & & & & & & & & & & Sakiadis & Blasius & Sakiadis & Blasius \\
\hline 0.5 & & & & & & & & & & -0.78544 & -0.78544 & 0.936655 & 0.888516 \\
\hline 1 & & & & & & & & & & -1.01835 & -1.01835 & 0.937290 & 0.900336 \\
\hline 1.5 & & & & & & & & & & -1.21873 & -1.21873 & 0.936622 & 0.909902 \\
\hline & 0.1 & & & & & & & & & -1.24575 & -1.24575 & 0.250565 & 0.264160 \\
\hline & 0.2 & & & & & & & & & -1.18593 & -1.18593 & 0.439774 & 0.446342 \\
\hline & 0.3 & & & & & & & & & -1.13951 & -1.13951 & 0.587918 & 0.579741 \\
\hline & & 0.1 & & & & & & & & 0.129467 & 0.129467 & 0.195989 & 0.192252 \\
\hline & & 0.2 & & & & & & & & 0.173690 & 0.173690 & 0.179586 & 0.187252 \\
\hline & & 0.3 & & & & & & & & 0.239373 & 0.239373 & 0.155735 & 0.180689 \\
\hline & & & 1 & & & & & & & -1.25849 & -1.25849 & 0.181948 & 0.133743 \\
\hline & & & 1.3 & & & & & & & -1.26199 & -1.26199 & 0.181351 & 0.137590 \\
\hline & & & 1.5 & & & & & & & -1.26327 & -1.26327 & 0.180743 & 0.139021 \\
\hline & & & & 0.1 & & & & & & -1.26675 & -1.26675 & 0.209885 & 0.216704 \\
\hline & & & & 0.3 & & & & & & -1.25364 & -1.25364 & 0.191466 & 0.217311 \\
\hline & & & & 0.5 & & & & & & -1.23978 & -1.23978 & 0.173100 & 0.217906 \\
\hline & & & & & 1 & & & & & -1.64437 & -1.64437 & 0.209036 & 0.222777 \\
\hline & & & & & 2 & & & & & -2.06750 & -2.06750 & 0.206701 & 0.223916 \\
\hline & & & & & 3 & & & & & -2.46725 & -2.46725 & 0.203845 & 0.224320 \\
\hline & & & & & & 0.2 & & & & -1.27427 & -1.27427 & 0.218363 & 0.215646 \\
\hline & & & & & & 0.4 & & & & -1.25978 & -1.25978 & 0.201979 & 0.217770 \\
\hline & & & & & & 0.6 & & & & -1.24127 & -1.24127 & 0.185176 & 0.219924 \\
\hline & & & & & & & 0.2 & & & -0.69823 & 1.019023 & 1.00037 & 0.939129 \\
\hline & & & & & & & 0.3 & & & -0.66309 & 1.060665 & 1.00271 & 0.940017 \\
\hline & & & & & & & 0.4 & & & -0.63657 & 1.090153 & 1.00398 & 0.940570 \\
\hline & & & & & & & & 0.5 & & -0.69823 & 1.019023 & 1.000374 & 0.939129 \\
\hline & & & & & & & & 1 & & -0.65672 & 1.054431 & 1.279711 & 1.206317 \\
\hline & & & & & & & & 1.5 & & -0.62449 & 1.081635 & 1.548226 & 1.465031 \\
\hline & & & & & & & & & 0.2 & -0.69823 & 1.019023 & 1.000374 & 0.939129 \\
\hline & & & & & & & & & 0.3 & -0.70488 & 1.008090 & 0.999673 & 0.938583 \\
\hline & & & & & & & & & 0.4 & -0.71104 & 0.997941 & 0.999013 & 0.938068 \\
\hline
\end{tabular}


Table 3. The values of $\operatorname{Re}_{x}^{1 / 2} C f$ and $\operatorname{Re}_{x}^{-1 / 2} \mathrm{Nu}$ for distinct values of the involved parameters in Sakiadis and Blasius flows in cases of $E=0.2$ and $\varepsilon=0.2$.

\begin{tabular}{|c|c|c|c|c|c|c|c|c|c|c|c|c|c|}
\hline \multirow[b]{2}{*}{$K$} & \multirow[b]{2}{*}{$\mathbf{B i}_{1}$} & \multirow[b]{2}{*}{$N t$} & \multirow[b]{2}{*}{$\mathrm{Nb}$} & \multirow[b]{2}{*}{ Ec } & \multirow[b]{2}{*}{$M$} & \multirow[b]{2}{*}{$A^{*}$} & \multirow[b]{2}{*}{$\mathbf{B i}_{2}$} & \multirow[b]{2}{*}{$N r$} & \multirow[b]{2}{*}{$\boldsymbol{K} \boldsymbol{r}$} & \multicolumn{2}{|c|}{$\operatorname{Re}_{x}^{1 / 2} C f$} & \multicolumn{2}{|c|}{$\operatorname{Re}_{x}^{-1 / 2} \mathrm{Nu}$} \\
\hline & & & & & & & & & & Sakiadis & Blasius & Sakiadis & Blasius \\
\hline 0.5 & & & & & & & & & & -0.72711 & 0.814655 & 0.939476 & 0.890692 \\
\hline 1 & & & & & & & & & & -0.94335 & 0.705546 & 0.939703 & 0.901598 \\
\hline 1.5 & & & & & & & & & & -1.12938 & 0.622592 & 0.938652 & 0.910526 \\
\hline & 0.1 & & & & & & & & & -1.17071 & 0.513540 & 0.255096 & 0.268215 \\
\hline & 0.2 & & & & & & & & & -1.09643 & 0.561116 & 0.447853 & 0.454167 \\
\hline & 0.3 & & & & & & & & & -1.04043 & 0.597545 & 0.598440 & 0.590227 \\
\hline & & 0.1 & & & & & & & & 0.137694 & 0.129467 & 0.188454 & 0.195989 \\
\hline & & 0.2 & & & & & & & & 0.189325 & 0.173690 & 0.170730 & 0.179586 \\
\hline & & 0.3 & & & & & & & & 0.274757 & 0.239373 & 0.143148 & 0.155735 \\
\hline & & & 1 & & & & & & & -1.17005 & 0.246588 & 0.192250 & 0.144241 \\
\hline & & & 1.3 & & & & & & & -1.17262 & 0.230030 & 0.191595 & 0.147730 \\
\hline & & & 1.5 & & & & & & & -1.17328 & 0.222222 & 0.190977 & 0.149016 \\
\hline & & & & 0.1 & & & & & & -1.19767 & 0.041969 & 0.217792 & 0.223030 \\
\hline & & & & 0.3 & & & & & & -1.17379 & 0.038660 & 0.201341 & 0.223679 \\
\hline & & & & 0.5 & & & & & & -1.15022 & 0.035459 & 0.184940 & 0.224305 \\
\hline & & & & & 1 & & & & & -1.55343 & 0.028338 & 0.216993 & 0.228745 \\
\hline & & & & & 2 & & & & & -1.94997 & 0.025553 & 0.214791 & 0.229826 \\
\hline & & & & & 3 & & & & & -2.32280 & 0.023687 & 0.212114 & 0.230208 \\
\hline & & & & & & 0.2 & & & & -1.21122 & 0.040769 & 0.225819 & 0.222170 \\
\hline & & & & & & 0.4 & & & & -1.18480 & 0.043283 & 0.210096 & 0.223863 \\
\hline & & & & & & 0.6 & & & & -1.16049 & 0.046335 & 0.195860 & 0.225419 \\
\hline & & & & & & & 0.2 & & & -0.65089 & 0.953555 & 1.004489 & 0.943062 \\
\hline & & & & & & & 0.3 & & & -0.61813 & 0.992334 & 1.006672 & 0.944308 \\
\hline & & & & & & & 0.4 & & & -0.59338 & 1.019789 & 1.008232 & 0.945133 \\
\hline & & & & & & & & 0.5 & & -0.65089 & 0.953555 & 1.004489 & 0.94306 \\
\hline & & & & & & & & 1 & & -0.60925 & 0.981699 & 1.28331 & 1.20994 \\
\hline & & & & & & & & 1.5 & & -0.57729 & 1.003277 & 1.55136 & 1.468387 \\
\hline & & & & & & & & & 0.2 & -0.65089 & 0.953555 & 1.004489 & 0.943062 \\
\hline & & & & & & & & & 0.3 & -0.65699 & 0.943536 & 1.003783 & 0.942441 \\
\hline & & & & & & & & & 0.4 & -0.66262 & 0.934235 & 1.003118 & 0.941858 \\
\hline
\end{tabular}

the friction factor coefficient and heat transfer in both Blasius and Sakiadis fluid flow cases. However, the inverse phenomenon can be observed for magnetic field and porosity parameters. Further, it is interesting to note that the Brownian motion parameter diminishes the skin friction coefficient and heat transfer rate for both Blasius and Sakiadis flows, and the heat transfer rate enhances sin Sakiadis flow and decelerates Blasius flow. However, the opposite trend can be seen for the case of thermophoresis parameter. The friction factor coefficient and heat transfer rates increase with increase in Biot numbers due to thermal diffusion. Finally, it is obvious that the heat transfer rate is enhanced with the increasing values of porosity, Biot 
Table 4. The values of $\mathrm{Re}_{x}^{-1 / 2} \mathrm{Sh}$ for distinct values of the involved parameters in Sakiadis and Blasius flows in both cases of $E=0, \varepsilon=0$ and $E=0.2, \varepsilon=0.2$.

\begin{tabular}{|c|c|c|c|c|c|c|c|c|c|c|c|c|c|}
\hline \multirow[b]{2}{*}{$K$} & \multirow[b]{2}{*}{$\mathbf{B i}_{1}$} & \multirow[b]{2}{*}{$N t$} & \multirow[b]{2}{*}{$\mathrm{Nb}$} & \multirow[b]{2}{*}{ Ec } & \multirow[b]{2}{*}{$M$} & \multirow[b]{2}{*}{$A^{*}$} & \multirow[b]{2}{*}{$\mathrm{Bi}_{2}$} & \multirow[b]{2}{*}{$N r$} & \multirow[b]{2}{*}{$\boldsymbol{K r}$} & \multicolumn{2}{|c|}{$E=0, \varepsilon=0$} & \multicolumn{2}{|c|}{$E=0.2, \varepsilon=0.2$} \\
\hline & & & & & & & & & & Sakiadis & Blasius & Sakiadis & Blasius \\
\hline 0.5 & & & & & & & & & & 0.216563 & 0.203628 & 0.218521 & 0.206783 \\
\hline 1 & & & & & & & & & & 0.230569 & 0.216911 & 0.232449 & 0.219780 \\
\hline 1.5 & & & & & & & & & & 0.241697 & 0.228478 & 0.243562 & 0.231145 \\
\hline & 0.1 & & & & & & & & & 0.237236 & 0.144745 & 0.238226 & 0.146286 \\
\hline & 0.2 & & & & & & & & & 0.242512 & 0.170498 & 0.244278 & 0.173641 \\
\hline & 0.3 & & & & & & & & & 0.246517 & 0.187140 & 0.248964 & 0.191579 \\
\hline & & 0.1 & & & & & & & & 0.102631 & 0.169125 & 0.102248 & 0.102631 \\
\hline & & 0.2 & & & & & & & & 0.043831 & 0.126553 & 0.040614 & 0.043831 \\
\hline & & 0.3 & & & & & & & & -0.04979 & 0.074405 & -0.06627 & -0.04978 \\
\hline & & & 1 & & & & & & & 0.153805 & -0.030891 & 0.155043 & -0.02673 \\
\hline & & & 1.3 & & & & & & & 0.161263 & -0.004319 & 0.162166 & -0.00147 \\
\hline & & & 1.5 & & & & & & & 0.164492 & 0.008246 & 0.165256 & 0.010621 \\
\hline & & & & 0.1 & & & & & & 0.131913 & 0.142226 & 0.133105 & 0.142962 \\
\hline & & & & 0.3 & & & & & & 0.123714 & 0.144632 & 0.126363 & 0.145545 \\
\hline & & & & 0.5 & & & & & & 0.113793 & 0.146976 & 0.119038 & 0.148040 \\
\hline & & & & & 1 & & & & & 0.146761 & 0.164426 & 0.147478 & 0.164444 \\
\hline & & & & & 2 & & & & & 0.152828 & 0.169150 & 0.153397 & 0.169069 \\
\hline & & & & & 3 & & & & & 0.156093 & 0.170945 & 0.156591 & 0.170825 \\
\hline & & & & & & 0.2 & & & & 0.137547 & 0.144400 & 0.138426 & 0.145137 \\
\hline & & & & & & 0.4 & & & & 0.125497 & 0.139936 & 0.127123 & 0.140683 \\
\hline & & & & & & 0.6 & & & & 0.111422 & 0.134910 & 0.112766 & 0.135756 \\
\hline & & & & & & & 0.2 & & & 0.117774 & 0.097489 & 0.118270 & 0.098331 \\
\hline & & & & & & & 0.3 & & & 0.153265 & 0.122747 & 0.153924 & 0.123825 \\
\hline & & & & & & & 0.4 & & & 0.180697 & 0.141332 & 0.181486 & 0.142585 \\
\hline & & & & & & & & 0.5 & & 0.117774 & 0.097489 & 0.118270 & 0.098331 \\
\hline & & & & & & & & 1 & & 0.121814 & 0.102232 & 0.122214 & 0.102893 \\
\hline & & & & & & & & 1.5 & & 0.124677 & 0.105578 & 0.125014 & 0.106124 \\
\hline & & & & & & & & & 0.2 & 0.117774 & 0.097489 & 0.118270 & 0.098331 \\
\hline & & & & & & & & & 0.3 & 0.120004 & 0.100793 & 0.120478 & 0.101595 \\
\hline & & & & & & & & & 0.4 & 0.122075 & 0.103861 & 0.122529 & 0.104625 \\
\hline
\end{tabular}

numbers, and thermal radiation in both the presence $(E=0.2, \varepsilon=0.2)$ and absence $(E=0, \varepsilon=0)$ of viscosity variation and conductivity variation parameters for Sakiadis and Blasius flow cases. Similarly, the friction factor is enhanced with raising values of Biot numbers, Thermophoresis, Eckert number, thermal radiation, and non-uniform heat source or sink. Interestingly, we found that the presence of variable thermal conductivity and viscosity leads to greater friction values than that without viscosity and variation parameters in both the Blasius and Sakiadis flow cases. The aforementioned results were achieved because of the inclusion of variable properties including the nature of the flow.

Table 4 shows the effect of various parameters on Sherwood number for both the Blasius and Sakiadis flows with $(E=0.2, \varepsilon=0.2)$ and $(E=0, \varepsilon=0)$ cases. The mass transfer rate is enhanced following an increase in the values of porosity, Biot numbers, Brownian motion, magnetic field, thermal radiation, and 
chemical reaction in both the Blasius and Sakiadis flow cases. Non-uniform heat source or sink acts as a heat absorption parameter. It is exciting to mention that the mass transfer rate is higher following the inclusion of variable properties than that without variable properties. As demonstrated by the result, the variable properties should be considered upon the need for greater mass transfer in the manufacturing and industrial processes.

\section{Conclusions}

Authors have neglected the importance of variable properties due to nonlinear nature of the flow. However, we realized their significance and took into consideration that fact that the industrial and manufacturing processes had buoyancy force with variable properties. This investigation considers free convection with variable properties of the flow to get the exact flow characteristics. It also examined the fluid velocity, temperature, and concentration distributions nature corresponding to distinct values of emerging constraints. The solutions were evaluated based on the numerical criteria. The following key points were extracted from this research:

1. The rate of mass transportation was weaker in Sakiadis flow situations as comparative to Blasius flow;

2. The Eckert number increased the friction-factors values for Blasius-Sakiadis flow problems;

3. The chemical reaction could diminish the thickness of the solutal layer;

4. The porosity parameter decelerated the friction factor coefficient;

5. The thermophoresis constraint enhanced the heat transport rates in the case of Blasius-Sakiadis fluid flow.

\section{Nomenclature}

$\begin{array}{ll}x, y & \text { Space co-ordinates } \\ C_{\infty}, T_{\infty} & \begin{array}{l}\text { Ambient concentration and } \\ \text { temperature }\end{array} \\ \nu & \text { Kinematic viscosity } \\ K(T) & \text { Variable conductivity } \\ k_{n} & \text { Chemical reaction rate } \\ k^{*} & \text { Stefan constant } \\ \varepsilon, \omega & \text { Small parameters of conductivity and } \\ & \text { viscosity } \\ \mu_{\infty} & \text { Ambient dynamic viscosity } \\ A & \text { Unsteady parameter } \\ E & \text { Viscosity variation parameter }\end{array}$

$\begin{array}{ll}\mathrm{Ec} & \text { Eckert number } \\ \mathrm{Pr} & \text { Prandtl number } \\ \mathrm{Bi}_{2} & \text { Concentration Biot number } \\ \lambda_{C} & \text { Concentration buoyancy parameter } \\ j_{w} & \text { Mass flux } \\ R_{x} & \text { Local Reynolds number } \\ \mathrm{Sh} & \text { Sherwood number } \\ (u, v) & \text { Velocity components } \\ \beta_{C}, \beta_{T} & \text { Coefficients of concentration and } \\ & \text { thermal expansions } \\ c_{p} & \text { Specific heat } \\ \rho & \text { Density } \\ \sigma^{*} & \text { Boltzmann constant } \\ h_{f_{1}}, h_{f_{2}} & \text { Heat and mass transfer coefficients } \\ k_{\infty} & \text { Ambient thermal conductivity } \\ \psi(x, y, t) & \text { Stream function } \\ M & \text { Magnetic field parameter } \\ K & \text { Porosity parameter } \\ N r & \text { Radiation parameter } \\ \mathrm{Bi} & \text { Thermal Biot number } \\ \lambda_{T} & \text { Thermal buoyancy parameter } \\ \tau_{w} & \text { Shear stress } \\ q_{w} & \text { Heat flux } \\ C f & \text { Skin-friction factor } \\ \mathrm{Nu} & \text { Nusselt number } \\ & \end{array}$

\section{References}

1. Blasius, H. "Grenzschichten in flussigkeiten mit kleiner Reibung", Z. Angew. Math. Physik, 56, pp. 1-37 (1908).

2. Sakiadis, B.C. "Boundary layer behavior on continuous solid surfaces: the boundary layer on a continuous flat surface", AIChE J., 7, pp. 221-225 (1961).

3. Pop, H. and Watanabe, W. "The effects of suction or injection in boundary layer flow and heat transfer on a continuous moving surface", Technis. Mech., 13, pp. 49-54 (1992).

4. Ishak, A., Yacob, N.A., and Bachok, N. "Radiation effects on the thermal boundary layer flow over a moving plate with convective boundary condition", Meccanica, 46, pp. 795-801 (2011).

5. Yao, S., Fang, T., and Zhong, Y. "Heat transfer of a generalized stretching/shrinking wall problem with convective boundary conditions", Commun. Nonlinear Sci. Numer. Simulat., 16, pp. 752-760 (2011).

6. Cortell, R. "Fluid flow and radiative nonlinear heat transfer over a stretching sheet", J. King Saud Uni.Sci., 26, pp. 161-167 (2014).

7. Khan, S.I., Khan, U., Ahmed, N., et al. "Effects of viscous dissipation and convective boundary conditions 
on Blasius and Sakiadis problems for Casson fluid", Natl. Acad. Sci. Lett., 38, pp. 247-250 (2015).

8. Olanrewaju, P.O., Gbadeyan, J.A., Agboola, O.O., et al. "Radiation and viscous dissipation effects for the Blasius and Sakiadis flows with a convective surface boundary condition", Int. J. Adv. Sci. Tech., 2, pp. 102-115 (2011).

9. Sheikholeslami, M. "New computational approach for exergy and entropy analysis of nanofluid under the impact of Lorentz force through a porous media", Comput. Methods Appl. Mech. Eng., 344, pp. 319-333 (2019).

10. Sheikholeslami, M. "Numerical approach for MHD $\mathrm{Al}_{2} \mathrm{O}_{3}$-water nanofluid transportation inside a permeable medium using innovative computer method", Comput. Methods Appl. Mech. Eng., 344, pp. 306-318 (2019).

11. Hsiao, K. "Stagnation electrical MHD nanofluid mixed convection with slip boundary on a stretching sheet", Appl. Thermal Eng., 98, pp. 850-861 (2016).

12. Hsiao, K. "Combined electrical MHD heat transfer thermal extrusion system using Maxwell fluid with radiative and viscous dissipation effects", Appl. Thermal Eng., 112, pp. 1281-1288 (2017).

13. Li, B., Zhang, W., Zhu, L., et al. "On mixed convection of two immiscible layers with a layer of non-Newtonian nanofluid in a vertical channel", Powder Tech., 310, pp. 351-358 (2017).

14. Si, X., Li, H., Zheng, L., et al. "A mixed convection flow and heat transfer of pseudo-plastic power law nanofluids past a stretching vertical plate", Int. J. Heat Mass Transf., 105, pp. 350-358 (2017).

15. Sheikholeslami, M. "Influence of magnetic field on nanofluid free convection in an open porous cavity by means of Lattice Boltzmann method", J. Mol. Liq., 234, pp. 364-374 (2017).

16. Zhu, J., Wang, S., Zheng, L., et al. "Heat transfer of nanofluids considering nanoparticle migration and second-order slip velocity", A ppl. Math. Mech., 38, pp. 125-136 (2017).

17. Abbasi, F.M., Hayat, T., Shehzad, S.A., et al. "Impact of Cattaneo-Christov heat flux on flow of two-types viscoelastic fluid in Darcy-Forchheimer porous medium", Int. J. Numer. Methods Heat Fluid Flow, 27, pp. 19551966 (2017).

18. Kumari, M. and Nath, G. "MHD boundary-layer flow of a non-Newtonian fluid over a continuously moving surface with a parallel free stream", Acta Mech., 146, pp. 139-150 (2001).

19. Akbar, N.S., Nadeem, S., Haq, R.U., et al. "Radiation effects on MHD stagnation point flow of nano fluid towards a stretching surface with convective boundary condition", Chin. J. Aeronaut., 26, pp. 1389-1397 (2013).
20. Devi, S.P.A. and Suriyakumar, P. "Effect of magnetic field on Blasius and Sakiadis flow of nanofluids past an inclined plate", J. Taibah Uni. Sci., 11, pp. 1275-1288 (2017).

21. Isa, S.S.P.M., Arifin, N.M., Nazar, R., et al. "The effect of convective boundary condition on MHD mixed convection boundary layer flow over an exponentially stretching vertical sheet", J. Phys.: Conf. Series, 949, pp. 1-14 (2017).

22. Hamad, M.A.A., Uddin, M.J., AND Ismail, A.I.M. "Radiation effects on heat and mass transfer in MHD stagnation-point flow over a permeable flat plate with thermal convective surface boundary condition, temperature dependent viscosity and thermal conductivity", Nuclear Eng. Design, 242, pp. 194-200 (2012).

23. Ferdows, M., Uddin, M.J., and Afify, A.A. "Scaling group transformation for MHD boundary layer free convective heat and mass transfer flow past a convectively heated nonlinear radiating stretching sheet", Int. J. Heat Mass Transf., 56, pp. 181-187 (2013).

24. Ullah, H., Islam, S., Khan, I., et al. "MHD boundary layer flow of an incompressible upper convected Maxwell fluid by optimal homotopy asymptotic method", Sci. Iran., 24, pp. 202-210 (2017).

25. Khan, M.I., Waqas, M., Hayat, T., et al. "A comparative study of Casson fluid with homogeneousheterogeneous reactions", J. Coll. Inter. Sci., 498, pp. 85-90 (2017).

26. Ramli, N., Ahmad, S., and Pop, I. "MHD forced convection flow and heat transfer of ferro fluids over a moving at plate with uniform heat flux and secondorder slip effects", Sci. Iran., 25, pp. 2186-2197 (2018).

27. Kumar, S.G., Varma, S.V.K., Kumar, R.V.M.S.S.K., et al. "Three-dimensional hydromagnetic convective flow of chemically reactive Williamson fluid with nonuniform heat absorption and generation", Int. J. Chem. Reac. Eng., 17, Article ID 20180118 (2019).

28. Hussain, S.M., Jain, J., Seth, G.S., et al. "Effect of thermal radiation on magneto-nanofluids free convective flow over an accelerated moving ramped temperature plate", Sci. Iran., 25, pp. 1243-1257 (2018).

29. Abbasi, F.M., Shanakhat, I., and Shehzad, S.A. "Entropy generation analysis in peristalsis of nanofluid with Ohmic heating and Hall effects", Phys. Scrip., 94, Article ID 025001 (2019).

30. Wang, J., Muhammad, R., Khan, M.I., et al. "Entropy optimized MHD nanomaterial flow subject to variable thicked surface", Comput. Methods Programs Biomed., 189, Article ID 105311 (2020).

31. Khan, M.I., Alzahrani, F., and Hobiny, A. "Heat transport and nonlinear mixed convective nanomaterial slip flow of Walter-B fluid containing gyrotactic microorganisms", Alex. Eng. J., 59, pp. 1761-1769 (2020). 
32. Abbas, S.Z., Khan, M.I., Kadry, S., et al. "Fully developed entropy optimized second order velocity slip MHD nanofluid flow with activation energy", Comput. Methods Programs Biomed., 190, Article ID 105362 (2020).

33. Grubka, L.J. and Bobba, K.M. "Heat transfer characteristics of a continuous, stretching surface with variable temperature", J. Heat Transf., 107, pp. 248250 (1985).

34. Ali, M.E. "Heat transfer characteristics of a continuous stretching surface", Warme and Stoffubertragung, 29, pp. 227-234 (1994).

35. Ishak, A., Nazar, R., and Pop, I. "Boundary layer flow and heat transfer over an unsteady stretching vertical surface", Meccanica, 44, pp. 369-375 (2009).

\section{Biographies}

R.L.V. Renuka Devi received her MPhil and PhD in Fluid Dynamics from Sri Venkateswara University, Tirupati, Andhra Pradesh, India. She has published 17 research papers in peer-reviewed ISI indexed international journals. Her research interests are fluid dynamics, magnetohydrodynamics, heat mass transfer, and non-Newtonian fluids.

S.V. Siva Rama Raju received his $\mathrm{PhD}$ degree in Mathematics from Andhra University, India. His research interests include graph theory, Lattice theory, and fluid dynamics. He has published several papers in international journals of high reputation. He received the BEST PAPER PRESENTED award for his paper entitled "Semi Complete Graphs" at the XIX Congress of Andhra Pradesh Society for Mathematical Sciences. At present, he is working as Assistant Professor at Abu
Dhabi Polytechnic, Abu Dhabi, UAE.

Chakravarthula S.K. Raju received his $\mathrm{PhD}$ degree from VIT University, Vellore. He published three books (one main author and 2 co-authors) and 100 research articles in peer-reviewed ISI indexed international journals. His research interests include theoretical simulation of nanofluid, ferrofluid, non-Newtonian fluids with numerical modelling with $\mathrm{C}$, Mathematica, and MATLAB. Currently, he is working as an Assistant Professor in GITAM School of Science. His name has been recently included in the top $2 \%$ scientists of the world data given by the Stanford University, USA.

Sabir Ali Shehzad is working as an Assistant Professor at the Department of Mathematics, COMSATS University Islamabad, Sahiwal Pakistan. He received his PhD in Fluid Mechanics from Quaid-I-Azam University, Islamabad, Pakistan in 2014. His main research interests are Newtonian and non-Newtonian fluids, nanofluids, and heat and mass transfer analysis. He has published $>300$ research articles in various wellknown international journals.

Fahad Munir Abbasi is working as an Assistant Professor at the Department of Mathematics, COMSATS University Islamabad, Islamabad Campus, Pakistan. He has completed his PhD in Fluid Mechanics from Quaid-I-Azam University, Islamabad, Pakistan. His main research interests are peristaltic flow, numerical modeling, and Newtonian and non-Newtonian fluids. He has published > 100 research articles in different highly reputed international journals. He is also the reviewer of more than 50 international journals. 